\title{
Nipple discharge
}

\section{Sasha Mazzarello BSc, Angel Arnaout MD}

\section{Nipple discharge is common and can be physiologic}

Nipple discharge is benign in most instances and is the third most common breast-related complaint, after breast pain and breast mass. ${ }^{1}$ About $50 \%$ of women in their reproductive years have physiologic nipple discharge that is characterized by bilateral, milky, green or yellow
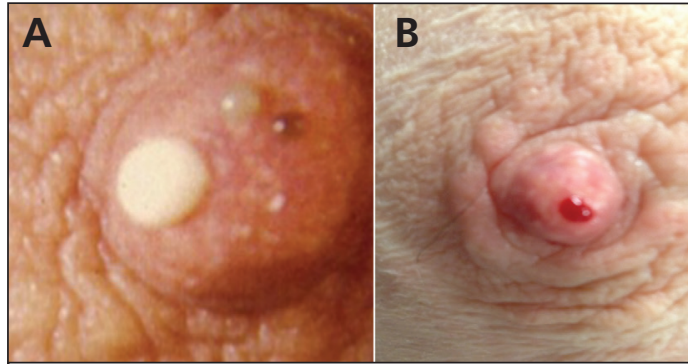

Figure 1: Nipple discharge from (A) multiple ducts (physiologic) and (B) a single duct (pathologic).

fluid expressed from multiple nipple duct openings and often associated with nipple stimulation (Figure 1$){ }^{2}$

Patients with pathologic nipple discharge should be referred for imaging to exclude carcinoma

Mammography (sensitivity may be decreased in younger patients) and retroareolar ultrasonography should be performed in all cases of pathologic nipple discharge., ${ }^{4,5}$ Galactography, and more recently magnetic resonance imaging, can be helpful in identifying an involved duct or papilloma. ${ }^{2,4}$ Patients with a palpable mass or a mass identified on imaging should undergo needle biopsy to exclude carcinoma. ${ }^{3,5}$
$C M A J$ invites submissions to "Five things to know about ..." Submit manuscripts online at http://mc.manuscriptcentral.com/cmaj

\section{All cases of pathologic nipple dis- charge need tissue diagnosis}

Physiologic nipple discharge tends to resolve spontaneously. Patients with pathologic discharge should have histologic evaluation through surgical excision of the involved duct (if no lesion is identified), or targeted excision of the lesion (if papilloma is identified) via open or needle biopsy. ${ }^{4,5}$

\section{References}

1. Hussain AN, Policarpio C, Vincent MT. Evaluating nipple discharge. Obstet Gynecol Surv 2006;61:278-83.

2. Onstad M, Stuckey A. Benign breast disorders. Obstet Gynecol Clin N Am 2013;40:459-73.

3. Masood S, Khalbuss WE. Nipple fluid cytology. Clin Lab Med 2005;25:787-95.

4. Markopoulos C, Mantas D, Kouskos E, et al. Surgical management of nipple discharge. Eur $J$ Gynecol Oncol 2006;27:275-8.

5. NCCN clinical practice guidelines in oncology: breast cancer screening and diagnosis: version 1. Fort Washington (PA): National Comprehensive Cancer Network; 2014. Available: www.nccn.org /professionals/physician_gls/pdf/breast-screening .pdf (accessed 2014 Dec. 4).
History and physical examination can distinguish physiologic from pathologic nipple discharge

Pathologic nipple discharge is spontaneous and often unilateral. It may arise from a single duct or be associated with a mass or new skin changes. It can be bloody, serous, green or black. ${ }^{1-3}$ Benign intraductal papilloma (48\%), ductal ectasia $(15 \%-20 \%)$ and carcinoma $(10 \%-$ $15 \%)$ are the most common causes. ${ }^{1}$

Milky discharge in patients who are not pregnant or lactating (galactorrhea) is often due to medications

Bilateral milky nipple discharge is appropriate during pregnancy and lactation, and it can last up to one year after delivery or after breastfeeding has stopped. Prolactin levels must be assessed to exclude endocrinopathy (> $20 \mathrm{ng} / \mathrm{mL}$ ) in patients who are not pregnant or lactating. ${ }^{2}$ Medications such as psychotropics, antihypertensives (e.g., reserpine, methyldopa, verapamil), opiates, prokinetics (e.g., metoclopramide) and $\mathrm{H}_{2}$-blockers (e.g., cimetidine) can cause galactorrhea. ${ }^{1,2}$

Competing interests: None declared.

This article has been peer reviewed.

Affiliations: Division of General Surgery (Arnaout), The Ottawa Hospital - General Campus, Ottawa, Ont.; Medical Oncology (Mazzarello), The Ottawa Hospital Cancer Centre, Ottawa, Ont.

Correspondence to: Angel Arnaout, anarnaout @ toh.on.ca

CMAJ 2015. DOI:10.1503/cmaj.140633 